the air inhaled shall not be of a lower temperature than from $60^{\circ}$ to $65^{\circ}$. As the germ thrives in moisture and fades in dry conditions, it is probable that the dryness of the air in a very warm room is of almost equal importance with the temperature. ${ }^{3}$ And this would seem to have a distinct bearing upon one point in the treatment of the "bronchitis." It is very usual in such cases to set the "bronchitis kettle" to work upon the stove, and as far as possible to keep the atmosphere of the room impregnated with moisture. But if the influenza germ loves moisture, and dies with dryness, this practice must necessarily be distinctly injurious; and, indeed, even in cases of ordinary bronchitis and pneumonia I have often thought the propriety of the use of this kettle at the very least doubtful, for necessarily the moisture in the air speedily becomes condensed and falls, with the liability to produce damp sheets, damp pillows, damp carpets, and damp valls.

\section{ON THE TREATMENT OF DETACHMENT OF THE RETINA.}

BY J. R. WOLFE, M.D., F.h.C.S.Ep. Melbourne, Victoria; late Ophthalmic Surgeon to the Glasgow Royal
Infirmary.

Ir is now nine years since I demonstrated in the National Ophthalmic Hospital of Paris my operation in cases of detachment of the retina. ${ }^{1}$ The recollection of one case is still vividly impressed upon my mind. When the eyes were opened on the fifth day after the operation, and the patient, Madame B., cried out, "Mon Dieu ! je vois!" I felt as if my head were touching the stars. The operation was then on its trial. A number of successful cases have since been reported from my Glasgow clinic and by others." But there is something intensely interesting in the case which $I$ am here to record.

On November 23rd, 1893, some days after my arrival in Melbourne, I was asked by one of the leading physicians to meet two well-known oculists in consultation in the case of the manager of a large financial establishment in Australasia who became totally blind from detachment of the retina of both eyes. He is a highly esteemed citizen, and his case has elicited the sympathy and concern of all classes of the community.

Cass.-Mr. W. C.. aged 59, of excellent health, six feet high, never had an illness till two years ago, when he suffered from an attack of influenza, which has left a tendency to frequent recurrence of naso-pharyngeal catarrh. He never had any eye trouble, but he is myopic (M. $6 \mathrm{D})$ without posterior staphyloma. About a year ago he began to feel some trouble in his left eye. He saw frequently what appeared like a shower of rain before him, and in shutting his eyes alternately he found that this optical delusion was owing to the condition of his left eye. The sight of that eye gradually deteriorated until it was entirely gone. In September last year his right eye began to be similarly affected, for which he was treated ; but the disease made rapid progress so that he could not sign his name, and had to do it by means of a seal. On November 20 th, however, he could not even see where to affix the seal.

The condition of the patient on November 23rd was : Left eye could not see the flame of a lamp before him in any direction; right eye could see the flame only outwards and downwards but not upwards and inwards. The map of the visual field, taken some days previous to the consultation, showed great limitation with central scotomata. But it was taken under unfavourable conditions, as he could then scarcely see the white spot of the perimeter. Ophthalmoscopic examination showed large retinal detachment in the

3 I have not overlooked the fact that Kitasato states that in culture experiments the bacilli do not thrive at temperatures below $37^{\circ} \mathrm{C}$. (=82.2 F.). But he further says that in gelatine at this temperature the cultures soon die; and, moreover, the two conditions in many ways are not comparable.

1 Communication addressed to the Académie de Mćdecine of Paris, October 14th, 1884 ; La France Médicale, and BRITISH MEDICAL JOURNAL, December, 1884.

2 BRITISH MEdical JourNat : Lancet, July, 1885 ; Original Contributions to Ophthalmic Surgery Churchill 1890. Report of M. Coppez to the French Ophthalmological Society, BRITISH MEDICAL JoURNAL, June 4th, 1887. lower and outer area with general retinal engorgement in both eyes. In the left a piece of retina was floating in the effusions, and the region of the macula was invaded.

The patient was ordered to keep the recumbent position for a few days, with the view of causing the effusions to gravitate downwards, and also to enable me to ascertain, by repeated examinations, where the effusion tended. The recumbent posture cleared up some part of the fundus.

On November 30 th, with the assistance of my confrieres and the physician in attendance, who administered chloroform, I operated on the left eye, the one first affected and the worst of the two. I made a vertical incision into the conjunctiva less than half an inch long, corresponding to the region of the detachment. The lips of the wound were kept separated in a horizontal direction by means of two strabismus hooks 1 then opened Tenon's capsule, laid bare the sclerotic and rotated the eyeball in such a manner as to expose the corresponding part towards which the fluid inclined. Into that part I introduced a narrow sclerotome obliquely, in such a manner that the edges of the scleral wound should overlap each other and not remain gaping when the instrument was withdrawn. Ouly two drops of yellow coloured fluid followed the withdrawal of the instrument. I then introduced into the wound my fine silver spatula, and pressing upon the lips of the wound a little more fluid came. After a few moments' rest I again introduced the spatula and rotated the eyeball so as to incline the cornea downwards and outwards, when there came a considerable quantity of fluid. After using friction upon the scleral wound, I brought the edges of the conjunctiva together by means of one silk ligature. The dressing consisted of court plaister, dry lint, and a bandage to the eyelids. No reaction occurred. On the fifth day the eyelids were opened, and everything looked well. The seventh day after the operation, the ligature being still in the conjunctiva, we examined the operated eye, and found that he could distinguish features and see colours. The visual field, taken in a rough way, was found satisfactory. On December $22 \mathrm{nd}$ vision was improving. He could see the time on a watch, and could write a short note with pencil. He left town for his country house, where on December 29 th he had a smart attack of influenza, which lasted for a few days. This, however, did not affect his sight.

On January 10th the visual field was taken by M'Hardy's

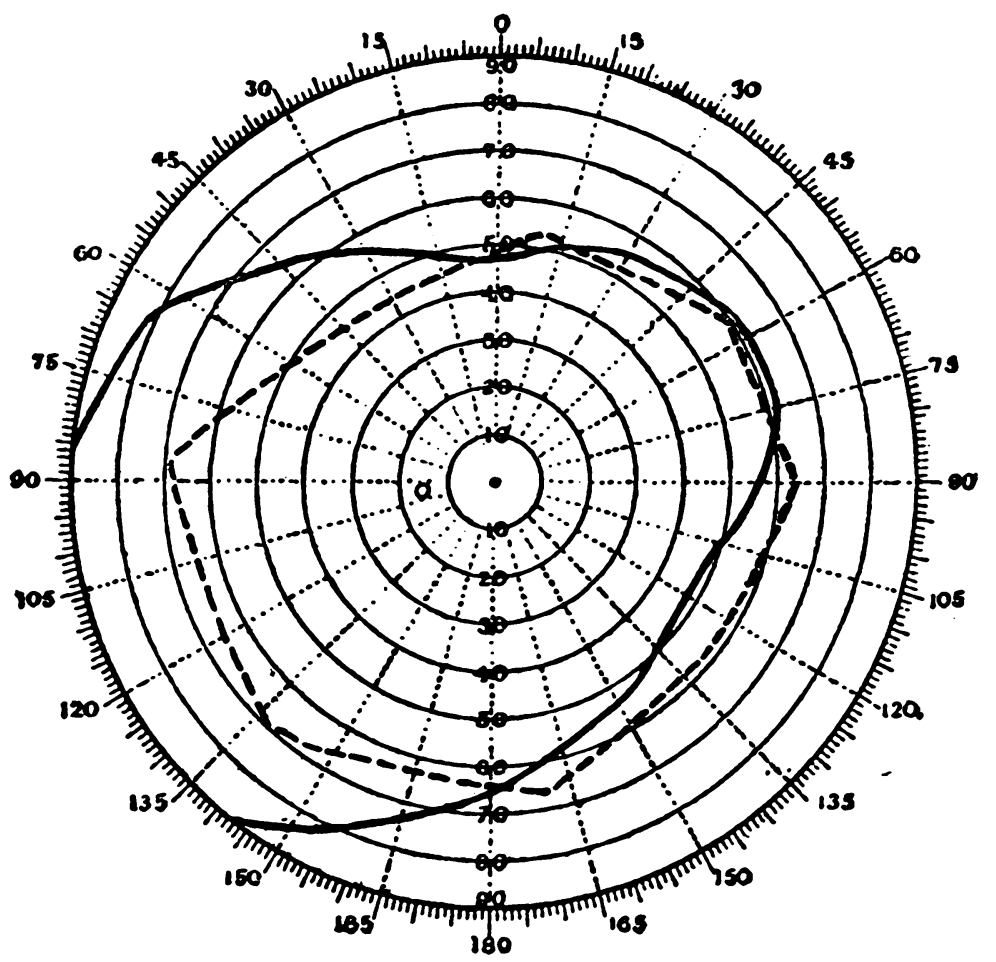

Left eye: The continuous line indicates $M^{\prime} H a r d y ' s$ average normal field and the dotted line shows the patient's usual field after operation. perimeter in the presence of the physician in attendance and one of the ophthalmic surgeons. The right eye had improved so that he could see persons with the outer part, and objects did not appear crooked as before. We intended to have operated on this eye also, but owing to the loss of time 
caused by the influenza we had to defer for the present, as his business requires his personal attendance.

Now (February 6th), after the lapse of two months, he can see the second pointer of a watch, reads 20 snellen at 3 feet distance and 20 Jaeger. He has been attending to l:is business five hours a-day, where he can see his clients and draft his letters, and does his work satisfactorily.

\section{ON HAMOPTYSIS. ${ }^{1}$}

By ARTHUR FONWELL, M.A., M.D.Cantab., F.R.C.I., Pliysician to the Queen's Hospital, Birminglıam.

[DR. Foxwrle first dealt in some detail with the vascular supply to the lungs, and discussed the general pathology of hrmoptysis, and various minor causes of its occurrence. He then continued :]

Thrombosis producing an infarct is not an uncommon cause of hæmoptysis. The amount of blood lost is not usuallg large and a fatal issue directly from the bleeding is extremely rare. This condition arises from various states of cardiac weakness but, once established, the pathology is identical. The pulmonary arterioles being non-anastomosing terminal vessels, the portion of lung beyond the block is deprived of all blood from the pulmonary artery, and also, which is the more important event from the hæmoptoic point of view, of the pressure which is derived from the pulmonary artery. The blocked area is now only supplied with blood from the bronchial, esophageal, and other small vessels ; these are sufficient to keep the area full, but have not enough pressure to maintain a proper flow against the reflux pressure from the veins, which pressure is maintained by the otherunblocked-branches of the pulmonary artery. Stagnation results; the affected tissues, including the walls of the involved vessels, necrose, and hæmoptysis often resul s; or the proximal portion of the artery containing the original thrombus may give way, and then a serious hæmorrhage, having behind it all the force of the pulmonary artery, may ensue.

It is evident, therefore, that the hæmoptysis does not occur at the moment of the occlusion, but only after an interval, during which vascular degeneration has taken place. allowing extravasation of ilood. Clinically, too, we tind this to be 80, for if immediately after a spitting of blood in, say, a case of mitral stenosis, we examine the chest, it is very rarely indeed that we shall be unable to discover localised signs of pleurisy and of inflammation of the lung parenchyma-that is, signs of degeneration in the area of the infarct.

Excessive strain of an otherwise healthy but weak heart may, though rarely, bring about a similar condition of things. Exhaustion of the right ventricle reduces the pressure in the pulmonary artery, and at the same time exhaustion of the left ventricle impedes the flow from the lungs into the left anricle; slowing and stagnation of the blood in the lungs ensue perhaps over a wide area, or, by inducing thrombosis, over two or three smaller ones, and, in a day or two, hæmoptysis arises. It is noteworthy that in all the records of fatal hæmoptysis from severe strain which I have read, the spitting of blood never occurred immediately after the exertion. Such was the nature of a case sent me by Dr. Newey, of Dudley, a few weeks ago. to young man, of somewhat feeble physique, ran more than two miles to fetch a doctor to his recently married wife, who had accidentally poisoned herself. He hurried home again, all the time and for some time fortnight later he had a large hæmoptysis, extending over four days, in all a quart. The blood was almost black, and came up in clots. After a rest of three weeks (more for the sake of precaution than because of serious ill-health) he returned to his occupation, that of a commercial traveller, and continued at it for ten weeks, when, after an unusually heavy journey in scotland, he had a return of similar hæmoptysis to a less extent. On its cessation Dr. Newey sent him to me. I found the right side of the heart much dilated, reaching 2 inches to the right of the sternum. The radial pulse was 120 and small, but of high tension. On examining the lungs, dulness was found throughout on the right, but this was most marked at the base ; the breath sounds were diminished very much at the base and bronchial in quality, while in the upper half very much at the base and bronchial in quality, while in the upper half they were less bronchial and fuller. My diagnosis was base full of efinsed blood and infarcted matter. with upper part of lung somewhat
collapsed, owing to d:stension of the lower half. I directed my atten-

A paper read before the Midland Medical Society, December 6th, 1893. tion to strengthening the heart with absolute rest, good food, digitalin, and nux vomica, adding some bromidia to soothe the nervous systom. I have heard sincee that he has much improved, though, as this was only some iortuight back, it is manifestly too soon to decide as to whether iny diagnosis or that of tuberculous hitemoptysis be the correct one.

[January, 1894. This patient has again consulted me, and the condition of the right lung has greatly intioved.]

Injury without puncture may so contuse a portion of lung that inflammation and suppuration result, when, if a vessel be involved, hiemoptysis may occur. I have now in the (Lueen's Hospital a little girl who was knocked down by the shaft of a cart hitting her just below and outside the right nipple. On the following day rather profuse hamoptyois occurred and continued for ten days; then, according to the history of Dr. Haynes, of Evesham, who sent me the casewhich history, by-the-by, was the model of what such histories ought to be-she had an attack of pneumonia of the right lung, from which after three weeks she appeared to be convalescent. But a fortnight later, with a sudden fit of coughing, a large quantity of pus was expectorated. with the usual signs of abscess of the lung. Later, signs of pleural effusion with blood-stained serum in small amount arose, at which time she came under my care. She is now fast recovering; seems perfectly well in herself, and the chest exhibits the usual signs of contracting cavity with much thickened pleura.

The explanation is evident. The blow contused the lung parenchyma, and so damaged the walls of one or more vessels that they gave way, hæmoptysis resulting. During the hamoptysis pneumonia arising from the contusion crept on, and, by the time the hæmoptysis had ceased, had fully declared itself. This pneumonia was of such severe type that a portion of the inflamed lung necrosed, became isolated, and broke down gradually into pus, which latter found its exit by a bronchus. Meanwhile, however, some inflammatory material was conveyed by the lymphatics or by direct extension to the pleura and set up pleurisy with effusion.

But it is in association with the tubercle bacillus that the great mass of hæmoptysis occurs. I say "in association" designedly, for that there is no indissoluble bond between the spitting of blood and the bacillus is evident in the fact that more than half the cases of tuberculous phthisis run their course without any hrmoptysis; in the fact that in acute pneumonic phthisis and in acute miliary tuberculosis of the lungs, two diseases where the bacilli lead the most virulent life and bring hasty death, hæmoptysis is most rare; in the fact again that in other primary lung affections, such as emphysema and fibroid disease, where bacilli play no rôle, yet hæmoptysis is at least as common as in those two previously mentioned, where they play their greatest rôle of all; and finally, in the fact that hæmoptysis unites with the bond of a common symptom these primary diseases with those which are purely secondary to cardiac mischief, a mischief which is supposed by many to be positively inimical to bacillary life.

Yet hæmoptysis and tubercle are too closely related to be looked on as mere concomitants, however much stress we may lay on the very great frequency of tuberculous phthisis as compared with all other diseases of the lungs.

Indeed, they both depend upon a common cause: the "dispositio catarrhalis" of the old writers, which I may best define as a tendency to a sluggish catarrh occurring in places where the circulation is feeble. The circulation is not sufficiently feeble to bring about degenerative inflammation and its resulting hremoptysis in previously well-disposed tissue, as we have seen may result from that far greater enfeeblement of circulation which follows cardiac failure; nor is the catarrhal tendency sufficiently active to start into being where the circulation is energetic, as occurs with the inselective catarrh of pneumonia. But where the catarrhal tendency and the feeble circulation both exist, there we have a constant focus of depressed activity, gifted with a dogged persistence which the strongest tissue must in time give way to, a veritable quicksand where it wallows helplessly, and in which at last, after passing through the stage of fatty degeneration, it dies suffocated. Such a slough of despond is the birthplace of hæmoptysis and the rich foster mother of the bacillus.

All hæmoptysis in tuberculous phthisis arises from a perforating ulceration of a vessel's wall, or from the solution of 